\title{
AN INVESTIGATION INTO THE IMPROVEMENT OF GRADUATE ATTRIBUTES WITHIN THE EGYPTIAN UNIVERSITY SECTOR
}

\author{
Iman Nassef \\ Dr., Arab Academy for Science and Technology and Maritime Transport, Egypt, \\ inassef@hotmail.com
}

\begin{abstract}
In Egypt earlier this century, the government recognised the importance of reforming its higher education sector to meet the challenges of the new era. One of these challenges was Egyptian employers' dissatisfaction with graduate attributes which were described as not meeting employment demands. To address such a problem, the Egyptian government, through a reform strategy, initiated a number of projects which among other things aimed to improve graduates' readiness for the labour market and thus reduce the skills gap. Yet, with all the initiatives achieved to date the problem still persists. This research has sought to study the skills gap problem in depth but within the scope of computer engineering undergraduate studies. It aims to understand the contextual factors affecting the effective implementation of graduate attributes in taught courses in Egyptian universities. To do this, a number of questions were posed, using semi-structured interviews, to a purposive sample of academics and graduates belonging to two different computer engineering undergraduate programmes; one private and the other public. To ensure the validity of the data, more information was collected from Egyptian employers as well as the documents that represent the different educational policies and practices implemented in both private and public programmes of study. Through thematic data analysis and by applying complexity theory as a conceptual framework, the study identified the different contextual factors that affected Egyptian academics' performance when teaching and learning graduate attributes in computer engineering undergraduate courses.
\end{abstract}

Keywords: University education in Egypt, the skills gap, higher education, education reform, education policy, complexity theory.

\section{INTRODUCTION}

Graduate attributes are important learning outcomes of higher education where many universities in Australia, UK and Egypt have implemented or currently in the process of implementing them in undergraduate degree courses. In most universities there has been significant work in the topic to improve 
graduate readiness for the labour market and thus reduce the skills gap and yet there is still uncertainty in the area of embedding graduate attributes into curricula (Jones 2013). The skills gap as defined by (Martin et al. 2005) is the difference between employers' expectations and what graduates actually deliver. This paper examines the reasons behind the limited implementation of graduate attributes including the reasons influencing the variation in their interpretation, providing a more theorised analysis of the specific nature of graduate attributes and the implications for higher education. It debates that graduate attributes are at the nexus of a number of complexities in the teaching environment and hence are influenced by context, and this paper investigates some of the underpinning reasons and in doing so argues that it is the very context specific nature of graduate attributes that explains their limited implementation. Policy has driven pedagogy without a critical examination of the context in which both are implemented (Jones 2013) and this paper explains the impact of that on graduate attributes implementation in courses. Complexity theory is the framework used for analysing the contextual factors affecting the ways in which graduate attributes are conceptualised in the Egyptian context which is an area that remains under explored.

There has been considerable research into graduate attributes. Much of this research has been based on discussing the initiatives done such as producing curriculum maps to show areas of graduate attributes and their development in taught courses using a number of tools such as: Gibbs et al.'s Matrix (Sumsion and Goodfellow 2004; Barrie 2006; Harvey and Kamvounias 2008), the graduate qualities grid (Medlin et al. 2003), and the transferable skills template (Atlay and Harris 2000). Also the attempts to explicitly articulate and implement various combinations of graduate attributes and career management skills using Bloom's Taxonomy in courses (Barrie 2004; Bridgstock 2009; Harpe and David 2012); adopting student centred, content focused strategies such as Work Integrated Learning (WIL) and Problem Based Learning (PBL) to allow students to actively share, practice and obtain feedback on their qualities (Hughes and Barrie 2010; Harpe and David 2012); improving academics' literacy in teaching and learning graduate attributes in courses (Harpe and David, 2012); and engaging industry members, careers office staff and students in the design of the curriculum (Leckey and McGuigan 1997). Specifically there has been studies which examine the relationship between graduate attributes and the teaching context (Jones 2009; Jones 2013), the barriers to the teaching of graduate attributes (Jones 2009) and the pedagogical, epistemological, structural and cultural factors affecting their teaching (Barrie 2004; Barrie 2006; Barrie 2007; Barrie 2009; Green et al 2009; Jones 2009; Hughes and Barrie 2010; Harpe and David 2012; Jones 2013). The definition of graduate attributes and their place in taught courses, academics conceptualisation of the concept and how it should be acquired by students have been discussed in length in the literature (Barrie 2004; Barrie 2006; Barrie 2007; Barrie 2009; Green et al 2009; Jones 2009; Hughes and Barrie 2010; Harpe and David 2012; Jones 2013). Rather than a renewed emphasis on these studies which were not sufficient in the context of teaching strategies to effectively promote the development of generic attributes, there is a need to a more pragmatic framework or a new lens that appreciates the critical connection between context and the notion of graduate attributes and it is these that this study sets out to explore using complexity theory.

Based on previous research, it is suggested that the teaching and learning of graduate attributes and thus the skills gap are not only affected by a number of conceptual, pedagogical, epistemological, structural and cultural factors (Barrie 2004; Barrie 2006; Barrie 2007; Barrie 2009; Green et al 2009; Jones 2009; Hughes and Barrie 2010; Harpe and David 2012; Jones 2013), and so the objective of this study is to identify using complexity theory the contextual factors that affect the skills gap between computer engineering undergraduate courses in Egyptian universities and the Egyptian labour market by asking two main questions:

1- What are the contextual factors which affect the skills gap within the Egyptian computer engineering undergraduate discipline?

2- How can the skills gap be reduced to meet the demands of the Egyptian computer engineering labour market?

\section{FRAMEWORK FOR ANALYSIS}

Complexity theory sometimes known as dynamic systems theory, or the theory of emergence (Haggis 2008), appears to provide a different way of conceptualisation. Complexity not only offers another theory, but a completely new departure for theory and also the conceptualisation of method. Cilliers (1998) differentiates between complex (having many parts, although not all of can be named and not all processes involved can be tracked or described) and complicated (having many parts, but each part can be explained). Haggis (2008) suggests that complexity could be conceptualised as consisting of a large number of smaller, overlapping types or organised open systems. Practices, cultures, grouping, individuals and institutions could all be seen as open systems which reflect different types of organisations (Cilliers 1998; Haggis 2008). 
With respect to the methods used to understand open systems, comparative and cross-sectional types of analysis as in figure 1A (whether in qualitative case studies or in large-scale surveys) discount the relationships which exist with the smaller units bounded by the case, in order to focus on the patterns which can be viewed when these smaller units are viewed in relation to each other (Haggis 2008). The interconnectedness of the elements within these types of units is too specific to be useful for the extraction a general principle. In contrast, dynamic systems theories as in figure $1 \mathrm{~B}$ focus upon the relationships and interactions that occur within open systems (Haggis 2008). A dynamic system consists of a large number of components, processes or activities that are interacting dynamically at a local level (Cilliers 1998). These multiple interactions are non-linear and involve feedback loops which continually modify parts of the system and the system itself (Cilliers 1998). As the system is open, the interactions can affect the boundaries of the system itself, and have effects beyond each part in the system. Moreover, because the interactions are local, such effects are distributed, rather than originating from any central source (Osberg 2002; Johnson 2001). If there are enough number of these interactions, and if they occur over a sufficiently long period of time, specific forms of order or organisation periodically emerge from within the system (Johnson 2001). Causality in complex systems is not A causes B but a state of deterministic emergence from non-linear interactions and thus is unexpected in relation to the principles governing the lower level domain (Osberg 2002). The outcome of these interactions cannot be predicted because it is impossible to know in advance what has interacted with what, or what will interact with what.

The simplified outline of complexity presented above gives an idea of how an ontology based on these thoughts can produce very different ways of conceptualising and analysing data in social research (Byrne 1997; Haggis 2008). First, the interactions are various and multiple and it is the multiplicity of the interactions through time that produces effects. Causality thus cannot be reduced to a limited or single number of factors, "as the factors are all crucially implicated in relation to each other" (Haggis 2008, p.167). The histories of these multiple interactions cannot be tracked, which shift from a focus on cause to a focus on effects (Byrne, 2005). Second, because of this multi-factor causality, elements that are removed, isolated or conceptually removed from the system of connected interactions in effect affect meaning in terms of understanding that system (Haggis 2008). The system itself has to be studied in terms of its interactions rather than identifying key elements in relation to smaller units within the system and comparing these to elements from other systems (Haggis 2008). As this kind of open dynamic system develops through time, it is constantly interacting with environmental factors or factors that exist beyond its boundaries (Haggis 2008), which immediately suggests a "thing" with "context" (Haggis 2008; p.167). Dynamic systems consist of interactions, which at any point in time constitute interactions that are part of the dynamic structures of other smaller or larger systems (Haggis 2008). These interactions are constantly reforming and combining in a unique way, yet are particular to that system. Based on that systems constituted of interactions, they cannot be reduced to objects or categories, so a way has to be found for conceptualising "event rather than structure" (Thomas 2002, p.430). Third, irregularity and unpredictability have to be accepted as structural aspects of interactions being investigated because of causality based on untraceable histories of multiple interactions (Haggis 2008). These features cannot be ignored or evened out. Unpredictability and irregularity are part of the structuring dynamics of complex systems even if they have happened too fast or too simultaneously to be noticed, but this does not mean they are absent (Haggis 2008). Fourth, complexity theory in comparison to other approaches offers an account of structure and also of coherence (Morrison 2008). "Structure here relates to processes of dynamic, de-centralised emergence which are being created as a result of local interactions" and which occur in relation to constraints that exist in and outside the system (Haggis 2008, p.168).

In a dynamic system, constraints are as much internal as external and as Haggis (2008) suggested each dynamic system has a starting point in time that emerges as a result of a set of historical interactions through time. This means that every dynamic system is unique, "even similar types of system will have emerged out of slightly different specific combinations of the numerous different interactions" which were possible in that place and at that time and will have specific histories which engage further specific interactions with specific combination of factors (Haggis 2008, p.168). Coherence is the existence of the system itself, in the sense of a shape and identity. Coherence makes it difficult to understand individuals when they are studied in relation to each other and is why generalising resultant individuals is difficult (Haggis 2008). In a cross-sectional analysis, what an individual does or says at a particular point in time is an emergence caused by an unseen history of interactions through time (Morrison 2008; Haggis 2008). When a system is observed from its outside, emergences may appear mystifying and messy, yet if it is observed from within, emergences are likely to be consistent with the history of interaction. 

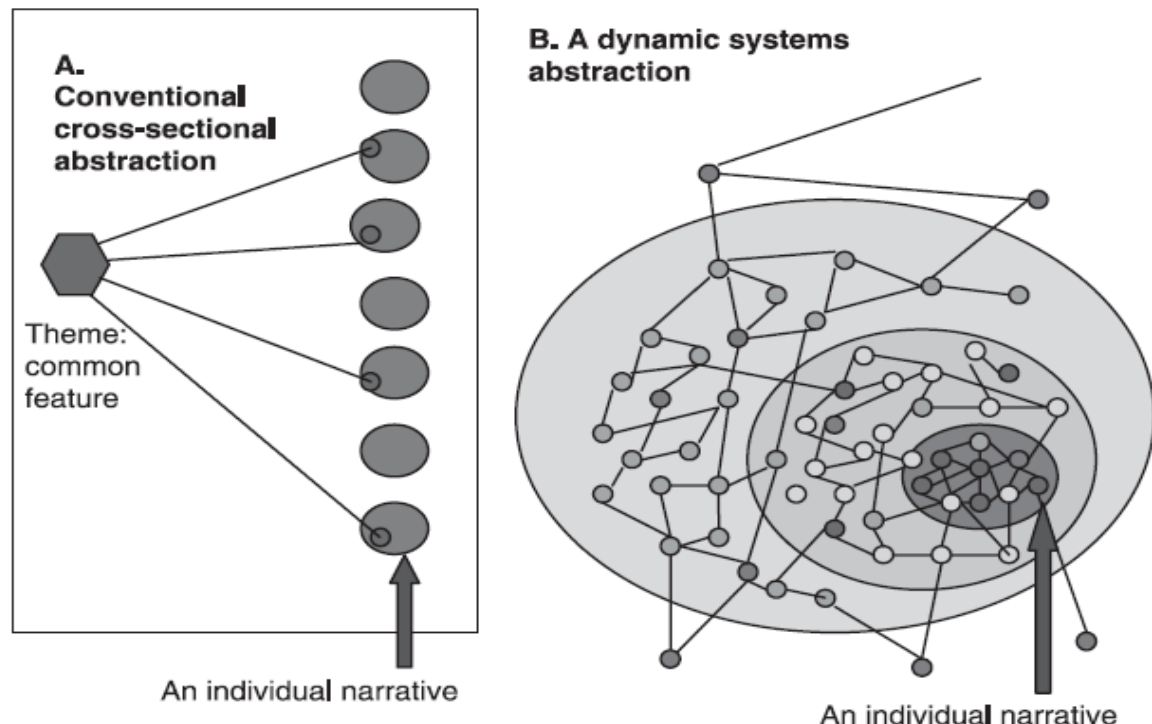

Figure 1: Conventional, cross sectional abstraction and dynamic systems abstraction (Haggis 2008; p.170)

\subsection{Egyptian universities as complex systems}

Complexity theory was a useful means of analysing the Egyptian university context as it takes into consideration and seeks to explain the critical connections, factors or causalities affecting the teaching and learning of graduate attributes and so is a way of understanding the different conceptualisations of graduate attributes that academics hold. Through the lens of complexity, the Egyptian higher education system is pictured as a complex structure consisting of a large number of smaller systems such as: universities, faculties, educational programmes, councils, committees, administrative structures, and stakeholders (e.g. academics, students, graduates and employers). These smaller systems across the time have interacted together through a number of activities, functions or work processes to produce a certain effect or result. However, these functions cannot be reduced to a single factor (i.e. A caused B) because they are all critically associated in relation to each other directly or indirectly. For example the Ministry of Higher Education governs universities through the Supreme Council of Universities which consists of universities presidents, vice presidents, and experts on higher education using a number of policies and procedures (SCU 2006; MOHE 2007; SCU 2010). Universities in turn supervise their faculties through internal regulations and bylaws (SCU 2006). Furthermore faculties administer academics, staff and students through their educational programmes. All these smaller systems and their interactions together across the time and through different educational processes and activities have allowed the emergence of the current status of university in Egypt including academics' conceptualisations and educational practices. It is possible that these interactions have happened too quickly to be predicted, yet their impact on education can be ignored. In this area complexity theory in comparison to all previous studies provides a different way of conceptualising higher education through the multi-layered exploration of context in terms of systems connectedness, multi-factor causalities, and emergence through history of time (Haggis 2008). Based on these assumptions the Egyptian university system was analysed contributing to the different contextual factors affecting the implementation of graduate attributes in computer engineering undergraduate courses. In detail these factors are presented and discussed in the results and discussion section.

\section{METHEDOLOGY}

The work of this study is based on different in depth semi-structured interviews with a purposive sample of 11 academics and 9 graduates in two different computer engineering undergraduate programmes; one that is private and another that is public. It is also based on collecting data from 10 Egyptian employers related to computer engineering and information technology (e.g. software development and network administration). The sample size for academics and graduates was based on a number of criteria such as: the years of work experience and nature of employment (part-time/full time). The programme of computer engineering was selected because computer engineers remain the nuclei of success for the Information Communication Technology (ICT) sector, which the Egyptian government has taken initiatives to invest in since 2000, in order to build a modern innovative-based economy (UNESCO 2007; Bond et al. 2013). 
In addition to interviews, copies of the Quality Assurance and Accreditation Handbook for higher education in Egypt (HEEP 2009b), the law governing Egyptian universities (SCU 2006), status reports which describe programmes and courses specifications were collected to understand the ways in which graduate attributes are described, understood and assessed by academics in the Egyptian educational context. Interviews were between 60-70 minutes in length. Interviews were semi-structured in nature with open ended questions to explore participants' perceptions in various areas related to graduate attributes. This technique was useful for asking probing questions as well as seeking clarifications from participants if necessary. Interviews were tape recorded and transcribed as verbatim. Data was analysed using template analysis which generated a number of codes through cross checking across all transcripts and documentations. From this coding, common patterns or themes were identified and refined. Relationships identified in the coding process were then confirmed, changed or discarded. The main themes into which data were coded included perceptions of graduate attributes, development of graduate attributes in courses, central role of faculty, quality measures and barriers to developing attributes in courses.

\section{RESULTS AND DISCUSSION}

With reference to the analysis of data and through an in-depth understanding of complexity theory ontological assumptions about context stripping, multiple processes, system connectedness, multi-factor causalities, de-centralised emergence, and its assertion that knowledge must be contextual, the factors affecting the teaching and learning of graduate attributes and hence the skills gap were identified, as follows.

First, the recruitment process adopted by the faculties allows only graduates of high academic excellence at the bachelor level to be appointed as academics without a teaching qualification and to continue in the system without penalisation or sifting at any stage (SCU 2006; UNESCO 2007). Such a recruitment system has indeed encouraged and privileged distinguished graduates to work within the system. However, it has also limited and constrained the emergence of new and innovative teaching and learning methods, thoughts and hence practices, and allowed these people to teach and assess students in the same way that they themselves were taught and assessed (UNESCO 2007; OECD 2010). As one of the public academics commented, "everyone tries to imitate his professor." Such a mechanical system not only creates an imitative or iterative method of course teaching, learning and assessment, but also promotes an academic/department culture/environment that embeds imitated thoughts, work practices and behaviours (Divedi 1995; Greenberg and Baron 2000; Johns and Saks 2001; Dawson 2010). As such, academics might have become less motivated and empowered to recognise, introduce and affect change in the implementation of their work practices thus affecting work effectiveness.

Second, academics are only required and encouraged to conduct academic disciplined research for their career progression as well as academic promotions according to the requirements of the Supreme Council and the internal regulations of their departments. In an academic teaching environment there is no obligation for Scholarship Of Teaching and Learning (SOTL) although they are encouraged to attend as part of their professional development a number of training courses offered by the National Centre for Faculty and Leadership Development (NCFLD) related to teaching, scientific research, communication and leadership (SCU 2006; HEEP 2009a). However, training is not always an effective mechanism for changing and developing cognition since it lacks continuity of practice, as suggested by Chalam (2006). Tying academics' promotions and progression in the system solely to technical disciplinary research or projects has directed academics to favour technical knowledge. Over time, this has created an academic culture that favours only technical knowledge.

Third, there is no formal feedback system to appraise academics on their academic performance (UNESCO 2007; OECD 2010; SPU 2010), hence they remain unaware of potential areas for their improvement. This could be argued to have affected academics' awareness, understanding, motivation and empowerment to introduce change to their learning and teaching practices hence leaving their behaviour unchanged.

Fourth, the work environment includes a number of variables, such as the pay scale, fringe benefits, remuneration, and lack of equal opportunities, which could be inappropriate, frustrating and give academics an excuse to stay detached from the system and its operational procedures, hence leaving teaching practices unchanged (UNESCO 2007; OECD 2010).

Fifth, there is no incentive or encouragement to conduct industry based research or collaborative projects although CEOs have invited academics to do so in their meetings with them. Sixth, industrial practitioners are not allowed to teach in academia because of the regulations set by the law governing Egyptian universities which allows only academics to teach (SCU 2006). These two last aspects have affected the potential to bring practitioners from the labour market into academia and vice versa, which would share the experiences of both sides (Leckey and McGuigan 1997; Harpe et al. 2000). 
Finally the faculty system does not encourage or provide incentives for industry secondments (SCU 2006, p.21). This indeed could be useful for academics to learn more about engineering technical and non technical practices through real life experiences which would potentially develop their awareness of how courses could be developed.

All these contextual factors when grouped together explain academics limited implementation of graduate attributes and the reasons affecting the variation of their interpretation arriving at an understanding of the reasons underpinning the skills gap in Egypt. It is noted, that these contextual factors are common for private and public courses of study which is attributed to the governance under which they operate. For instance, they are both governed by the same law which controls Egyptian universities (SCU 2006), and the same Council which is the Supreme Council of Universities (SCU 2006; MOHE 2007; SCU 2010). In order to improve the skills gap, this study suggests to higher education authorities the need to change the current policies implemented for teaching and learning undergraduate courses of study. This includes changes to procedures related (but not limited to): graduate recruitment in academia; academics' scholarship for teaching and learning, the pay scale, fringe benefits and remuneration; academics' career development within the academic system (i.e. progression, promotion and appraisal), incentives to conduct industry based research collaborative projects or industry secondments and industrial practitioners teaching in academia.

This study suggests reducing the skills gap priority begins by changing the Egyptian law governing universities which dates back to 1972 (SCU 2006). This is because the law is the main driver of all universities' (public and private) work operations. In that regard, the law clauses which relate to graduate recruitment should stipulate that new graduates are employed according to their: awareness of disciplinary knowledge, personal attributes, potential to teach in academia, previous work experience in the field related to his/her degree specification (preferable one year or more), assessment and feedback on internships/training work while in university, and that there should be no preference given, as appropriate, to the recruitment of graduates to the school from which they graduated. The law should also encourage public universities to recruit graduates of other universities, either within Egypt or outside, into their academic system to create an academic culture that allows the diversification of personal attributes, ideas, and disciplinary knowledge. Such a move would help to improve academics' performance in relation to teaching and learning graduate attributes in courses of study.

Similarly, as regards academics' promotion and progression in the academic system, which is currently based on disciplinary research, the law should be amended to allow interested academics more flexibility for promotion and progression based on pedagogic research related to their disciplines. This would improve academics' teaching and learning practices, which in turn would create a culture that appreciates such practices, rather than one that values only disciplinary knowledge as is currently the case. Also, there should be more formalised relationships between industry/the labour market and the university in the form of industry/the labour market based research, community service, collaborative projects or industry/labour market secondments for interested academics. Such a relationship should take into account the necessary incentives that would encourage academics to perform these tasks. However, it should not only depend on the university, but also on the industry/the labour market, where assessment of interest of both sides should be taken into consideration to decide on the most suitable approach for their mutual relationship. The aim of these formalities is to keep academics aware of the labour market's most needed attributes for employment as well as to keep the labour market aware of the disciplinary knowledge and attributes taught in faculties, in order to bridge the skills gap between the labour market and academia. It is also suggested that academics are appraised for progression in the academic system based on their personal attributes and abilities to teach students rather than just allowing students to evaluate them based on their ability to teach disciplinary knowledge.

With regard to employers, the law should encourage universities to invite them to lecture on a course of study or to conduct lectures on a frequent basis. Universities could also invite employers to review the attributes embedded in taught courses and how they are taught and learned and to give feedback on areas for improvement. The aim is to create a learning environment that is similar to the workplace to feed in experiences from industry/the labour market into the design of courses. The main focus of these lectures should be based on the improvement of disciplinary knowledge and awareness of the labour markets' needs, particularly with regard to graduate attributes. These visits could be an opportunity for academics to show case how well they are addressing labour market needs in their courses.

Finally, academics need to be kept motivated towards the effective implementation of attributes in courses. This includes providing the appropriate rewards in the form of salary increases, fringe benefits, and remuneration. Now that the higher education budget accounts for $4 \%$ of Egypt's GDP, funds for remuneration and rewards should be considered as part of the university annual budget set for education 
and this should be announced to all academics to inform and motivate them about the value of effectively implementing graduate attributes in taught courses.

In order to validate these research findings a focus group was set up. It consisted of a number of experts in the field of higher education. The outcomes of the focus group were indeed useful in providing a broad understanding of the research findings in relation to the current policies implemented in Egypt, particularly where areas for improvement were needed.

\section{CONCLUSIONS}

The findings of this study have contributed to new knowledge by suggesting to higher education authorities that if an academic is to engage in teaching graduate attributes in undergraduate courses, attention should focus on a number of contextual factors. For public and private computer engineering courses of study, these are: academics' recruitment, promotion and progression procedures, department/faculty culture which has an orientation towards disciplinary knowledge, lack of scholarship of learning and teaching, performance appraisal, the pay scale, fringe benefits and remuneration, no incentive to conduct industry based research, collaborative projects or industry secondments and industrial practitioners are not allowed to teach in academia. The reason that both learning environments reflected similar factors is grounded to the Egyptian higher education context which governs universities with the same law (SCU 2006). The key conclusion from this research is that it is possible, given the appropriate contextual conditions, that the skills gap can be reduced between undergraduate degree courses and the Egyptian labour market. This study has shown that a concept such as graduate attributes is at the nexus of a number of complexities that affect their teaching and assessment in taught courses. Yet, these complexities are not only pedagogical, epistemological or cultural but also contextual. Based on this, it could be said that graduate attributes are context specific that is they have a very situated nature that is influenced by the activity, discipline, culture or context in which they are taught. To the end of this study it could be understood that because the contextual conditions influencing the effective implementation of graduate attributes were overlooked in contexts of studies that the implementation of graduate attributes was patchy and of limited success.

\section{REFERENCE LIST}

Atlay, M., and Harris, R., 2000. An Institutional Approach to Developing Students' Transferable' Skills. Innovations in Education \& Training International, 37 (1), 76-84.

Barrie, S., C., 2004. A Research-Based Approach to Generic Graduate Attributes Policy. Higher Education Research \& Development, 23 (3), 261-275.

Barrie, S., C., 2006. Understanding What We Mean by the Generic Attributes of Graduates. Higher Education, 51 (2), 215-241.

Barrie, S., C., 2007. A Conceptual Framework for the teaching and Learning of Generic Graduate Attributes. Higher Education, 32 (4), 439-458.

Barrie, S., C., 2009. The National Gap: Institutional Systems and Curriculum Renewal to Achieve Graduate Attributes.http://www.herdsa.org.au/wp-content/uploads/HERDSA-News-Volume-31-No-3-December2009-with-banner.pdf.

Bridgstock, R., 2009. The Graduate Attributes We've Overlooked: Enhancing Graduate Employability through Career Management Skills. Higher Education Research \& Development, 28 (1), 31-44.

Bond, M., Maram, H., Soliman, A., and Khattab, R., 2013. Science and Innovation in Egypt. http://royalsociety.org/uploadedFiles/Royal_Society_Content/policy/projects/atlas-islamicworld/Atlas_Egypt.pdf.

Byrne, D., 1997. Complexity Theory And Social Research. Social Research Update, 18, 1-6.

Byrne, D., 2005. Complexity, configurations and cases. Theory, Culture and Society, 22 (5), 95-111.

Chalam, K., S., 2006. Modern Techniques of Teaching and Staff Development. Delhi: Anmol Publishers.

Cilliers, P., 1998. Complexity and Postmodernism. London: Routledge

Dawson, C., S., 2010. Leading Culture Change: What Every CEO Needs to Know. Palo Alto, CA, USA: Stanford University Press.

Divedi, R., K., 1995. Organizational Culture and Performance. New Delhi: M D Publications. 
Green, W., Hammer, S., and Star, C., 2009. Facing Up to the Challenge: Why Is It So Hard to Develop Graduate Attributes? Higher Education Research \& Development, 28 (1), 17-29.

Greenberg, J., and Baron, R., A., 2000. Behaviour in Organisations. $7^{\text {th }}$ ed. New Jersey: Prentice Hall.

Haggis, T., 2008. Knowledge Must Be Contextual: Some Possible Implications of Complexity and Dynamic Systems Theories for Educational Research. Educational Philosophy and Theory, 40 (1), 158-176.

Harpe, B., D., L., and David, C., 2012. Major Influences on the Teaching and Assessment of Graduate Attributes. Higher Education Research \& Development, 31 (4), 493-510.

Harpe, B., D., L., Radloff, A., and Wyber, J., 2000. Quality and Generic (professional) Skills. Quality in Higher Education, 6 (3), 231-243

Harvey, A., and Kamvounias, P., 2008. Bridging the Implementation Gap: A Teacher as Learner Approach to Teaching and Learning Policy. Higher Education Research \& Development, 27(1), 31-41.

Higher Education Enhancement Project (HEEP), 2009a. The Strategic Plan for Higher Education Structure Development. http://www.heep.edu.eg/download_center/1.pdf.

Higher Education Enhancement Project (HEEP), 2009b. World Bank: Borrower's Report Implementation Completion and Results Report, IBRD Loan No. 4658-egy. http://www.heep.edu.eg/WB.htm.

Hughes, C., and Barrie, S., 2010. Influences on the Assessment of Graduate Attributes in Higher Education. Assessment \& Evaluation in Higher education, 35 (3), 325-334.

Johns, G., and Saks, A., 2001. Organizational Behaviour: Understanding and Managing Life At Work. $5^{\text {th }}$ ed. Toronto: Pearson education.

Johnson, S., 2001. Emergence. London: Penguin.

Jones, A., 2009. Generic Attributes as Espoused Theory: The Importance of Context. Higher Education, 58 (2), 175-191.

Jones, A., 2013. There Is Nothing Generic About Graduate Attributes: Unpacking the Scope of Context. Journal of Further and Higher Education, 37 (5), 591-605.

Hughes, C., and Barrie, S., 2010. Influences on the assessment of graduate attributes in higher education. Assessment \& Evaluation in Higher education, 35 (3), 325-334.

Leckey, J., F., and Mcguigan, M., A., 1997. Right tracks-wrong rails: The development of generic skills in higher education. Research in Higher Education, 38 (3), 365-378.

Leckey, J., F., and Mcguigan, M., A., 1997. Right Tracks-Wrong Rails: The Development of Generic Skills in Higher Education. Research in Higher Education, 38 (3), 365-378.

Martin, R., Maytham, B., Case, J., and Fraser, D., 2005. Engineering Graduates' Perceptions of How Well They Were Prepared to Work In Industry. European Journal of Engineering Education, 30 (2), 167180.

Medlin, J., Graves, C., and Mcgowan, S., 2003. Using Diverse Professional Teams and a Graduate Qualities Framework to Develop Generic Skills within a Commerce Degree. Innovations in Education \& Teaching International, 40 (1), 61.

Ministry of Higher Education (MOHE), 2007. Guide to Higher Education in Egypt. http://www.mohecasm.edu.eg/Main_menu/version/daleel_talem_aaly/English.pdf.

Morrison, K., 2008. Educational Philosophy and The Challenge Of Complexity Theory. Educational Philosophy and Theory, 40 (1), 16-30.

Osberg, D., 2005. Curriculum, Complexity and Representation. Unpublished PhD Thesis, The Open University, Milton Keynes.

Sumsion, J., and Goodfellow, J., 2004. Identifying Generic Skills through Curriculum Mapping: A Critical Evaluation. Higher Education Research \& Development, 23 (3), 329-346.

Supreme Council of Universities (SCU), 2006. The Universities Law. http://www.scu.eun.eg/wps/portal

Supreme Council of Universities (SCU), 2010. Supreme Council of Universities Guide. http://www.scu.eun.eg/wps/portal. 
The Organization for Economic Co-operation and Development (OECD), 2010. Higher Education in Egypt Report of the 2008-09 International Review.

http://siteresources.worldbank.org/INTEGYPT/Resources/REPORTHigherEducationinEgypt2010FINAL-ENGLISH.pdf.

Thomas, G., 2002. Theory's Spell on Qualitative Inquiry and Educational Research. British Educational Research Journal, 28 (3), 419-435.

UNESCO, 2007. University Engineering Education in Egypt: Analysis and Projection Optimisation Analysis.http://www.MOHEspu.org/new/admin/uploads/resources/University\%20Engineering\%2 0Education\%20in\%20Egypt\%20Analysis\%20and\%20Projections\%200ptimization20070903073618.pdf. 